\title{
Prevalence and Clinical Manifestations of Helicobacter Pylori with Reference to Histopathological Diagnosis
}

\section{Makaju R, Dhakal B, Dhakal R}

\author{
Corresponding Author \\ Ramesh Makaju \\ Department of Pathology, \\ Kathmandu University School of Medical Sciences, \\ Dhulikhel, Kavre, Nepal. \\ E-mail:makajuram@yahoo.com
}

Citation

Makaju R, Dhakal B, Dhakal R. Prevalence and Clinical Manifestations of Helicobacter Pylori with Reference to Histopathological Diagnosis. Kathmandu Univ Med J. 2020;69(1):64-7.

\begin{abstract}
Background

Helicobacter pylori infection is on a steep decline in most of the developed countries; however, in developing countries like Nepal such steep decline is not seen. This may be due to failure of treatment regimens and emergence of drug resistance. Our previous study done in $2004 / 2005$ showed $38 \%$ prevalence of Helicobacter pylori. The present study has been conducted to review the prevalence and clinical diagnosis of Helicobacter pylori with reference to histo-pathological diagnosis.
\end{abstract}

\section{Method}

This was retrospective study done at Dhulikhel Hospital, Kathmandu University Hospital over a period of 13 years from January 2006 to December 2018. Helicobacter pylori proven cases were retrospectively analyzed with clinical features and endoscopy findings. The clinical picture were categorized into antral gastritis, gastroduodenits, erosive duodenitis, acid peptic disease, reflux esophagitis, hiatal hernia, polyp, ulcer (gastric and duodenal), acute abdomen, upper gastrointestinal bleeding and malignancy.

\section{Result}

A total of 1624 upper gastrointestinal endoscopy biopsies were taken during the study period. Helicobacter pylori infection was seen in 618 (38.0\%) cases out of 1624 cases. Helicobacter pylori were seen in 349 male and 269 female patients with male to female ratio of 1.29:1. Clinically, gastritis 210 (41.4\%), acid peptic disease74 $(42.7 \%)$, gastroduodenitis $46(37.7 \%)$, reflux esophagitis $38(52.7 \%)$, gastric ulcer 48 (28.4\%), duodenal ulcer 34 (53.1\%) and acute abdomen 50 (42.3\%) cases were seen respectively.

\section{Conclusion}

Most commonly Helicobacter pylori cause chronic gastritis in our context. There is no significant change in prevalence of Helicobacter pylori infection as compared to our previous study (2004/05). This needs proper management of Helicobacter pylori infection to prevent serious complication such as gastric cancer in our part of the world.

\section{KEY WORDS}

Helicobacter Pylori, Histopathological diagnosis, Prevalence 


\section{INTRODUCTION}

Helicobacter pylori is a gram-negative bacterium colonizing human stomach and associated with numerous gastrointestinal diseases like chronic gastritis, peptic ulcer diseases, and gastric cancer in adults. ${ }^{1,2}$ It is a ubiquitous gastrointestinal organism which infects more than half the population of the world. ${ }^{3}$ Our previous study done in 2004/2005 showed $38 \%$ prevalence of $H$. pylori in our institution. $^{4}$

Nevertheless, $H$. pylori infection is on a steep decline in most of the developed countries mainly due to the success of combination therapies and improved personal hygiene and community sanitation to prevent re infection. However, in developing countries like Nepal such steep decline is not seen. This may be due to failure of treatment regimens and emergence of drug resistance. ${ }^{5,6}$ In view of frequent treatment failure, this study has been conducted to review the prevalence and clinical diagnosis of $H$. pylori with reference to histopathological diagnosis in our institution.

\section{METHODS}

This was retrospective study done at Dhulikhel Hospital, Kathmandu University Hospital over a period of 13 years from January 2006 to December 2018. Data were collected and analysed from all individuals who had undergone gastric biopsy during the procedure of $\mathrm{Gl}$ endoscopy or endoscopic retrograde cholangiopancreatography (ERCP). The prior permission from the institutional review committee was obtained to initiate this study.

The biopsy specimens were taken from the suspicious parts which commonly include antrum, corpus, incisura and sometimes from duodenum. The biopsy specimens were fixed in $10 \%$ buffered formalin, processed, embedded in paraffin wax and the cut sections were stained with Hematoxylin and Eosin (H\&E) and Giemsa stain. Giemsa stained sections were observed for H. pylori. H. pylori were considered as positive when spiral or curved organisms present on superficial mucosal layer or deeper crypts. Histological reporting was done by pathologists using Modified Sidney system which includes inflammation, activity, atrophy, intestinal metaplasia, and $H$. pylori colonization.

H. pylori proven cases were retrospectively analyzed with clinical features and endoscopy findings. The clinical picture were categorized into antral gastritis, gastroduodenits, erosive duodenitis, acid peptic disease, reflux esophagitis, hiatal hernia, polyp, ulcer (gastric and duodenal), acute abdomen, UGI bleeding and malignant mass.

Data were analysed using Statistical Package of Social Sciences (SPSS) version 16.

\section{RESULTS}

A total of 1624 Upper Gastrointestinal (UGI) endoscopy biopsies were taken during the study period. Emphasis was given to take at least 5 biopsies from representative sections (according to Sydney classification). The age of the patients ranged from 18-75 years with the mean age of 45.9 years.

The $H$. pylori infection was observed in 618 cases out of 1624 cases. $H$. pylori were seen in 349 male and 269 female patients with male to female ratio of 1.29:1. Our study showed the decreasing trend of $H$. pylori positive case from 2006 to 2014 but, the positive cases increased from 2015 (fig. 1). The minimum numbers of $H$. pylori positive cases were reported in 2012 whereas maximum being at the end of 2018. (fig. 1)

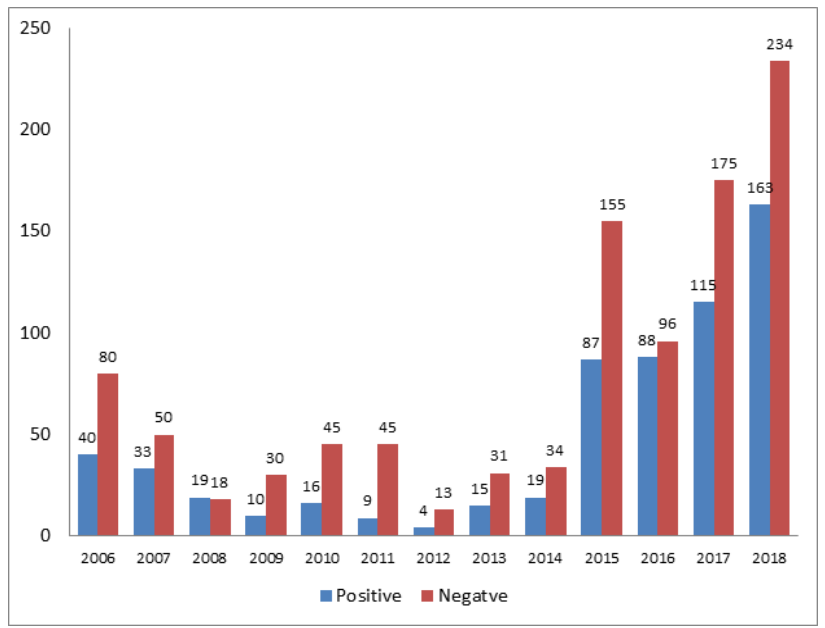

Figure 1. Number of $\boldsymbol{H}$. pylori positive and negative cases year wise.

Further, the comparison of clinical manifestations with endoscopic findings revealed that more than $50 \%$ of $\mathrm{H}$. pylori positive cases were found to be in duodenal ulcer/ erosion and reflux esophigitis. The $H$. pylori positive cases were also prominent in Gastritis (41.4\%), acid peptic diseases (42.7\%), acute abdomen (42.3\%) and UGI bleeding $(40.7 \%)$ as shown in the table 1.

There is a rise in number of endoscopic cases and ultimately the number of $H$. pylori diagnosed cases compared to our study of 2004/2005 which showed a total of 76 (33.9\%) patients (male 50 and female 26) infected by $\mathrm{H}$. pylori out of 224 patients who underwent endoscopic biopsy. However the rise is not significant as the number of $H$. pylori cases increases with the increase in number of endoscopic procedures.

\section{DISCUSSION}

The management of patients who presents with symptoms of upper Gl comprised of initial history taking, physical examination, upper GI endoscopy and finally followed by biopsy with histopathological diagnosis. ${ }^{7}$ 
Table 1. Clinical diagnosis and $\boldsymbol{H}$. pylori $(\mathrm{n}=1624)$

\begin{tabular}{|lll|}
\hline Clinical Diagnosis & $\begin{array}{l}\text { No. of } \\
\text { cases }\end{array}$ & $\begin{array}{l}\text { No. of } \boldsymbol{H .} \text { pylori } \\
\text { positive cases (\%) }\end{array}$ \\
\hline Gastritis & 507 & $210(41.4)$ \\
\hline Acid peptic disease/dyspepsia & 173 & $74(42.7)$ \\
\hline Gastroduodenits & 122 & $46(37.7)$ \\
\hline Reflux esophagitis & 72 & $38(52.7)$ \\
\hline Gastric Ulcer & 169 & $48(28.4)$ \\
\hline Duodenal ulcer/erosion & 64 & $34(53.1)$ \\
\hline Acute abdomen & 118 & $50(42.3)$ \\
\hline Erythematous mucosa & 117 & $38(32.4)$ \\
\hline Hiatal Hernia & 53 & $12(22.6)$ \\
\hline Polyp & 35 & $9(25.7)$ \\
\hline UGI bleeding & 27 & $11(40.7)$ \\
\hline Malignancy & 36 & $10(27.7)$ \\
\hline Others & 131 & $38(29.0)$ \\
\hline
\end{tabular}

In this present study the age of the patients with upper GI symptoms range from 18 - 75 years with the mean age of 45.9 years. The data are similar with the study conducted by $\mathrm{KC}$ et al. whose study showed age range of $16-94$ years with the mean of 41.7 years. ${ }^{7}$

H. pylori remains the most common cause of chronic gastritis. $^{8}$ Our study showed that $38.0 \%$ of the total patients performed endoscopy was infected with $H$. pylori. The study was similar with our previous study. ${ }^{4}$ The overall total prevalence of $H$. pylori infection (38.0\%) in present study is lower than those of the other studies (49-70\%) done in and outside Nepal. ${ }^{9-11}$ The lower prevalence in our study could be due to low number of biopsy material taken from the suspicious site while performing endoscopy. $H$. pylori organism in the stomach is distributed in patches so that it can give rise to false negative results if biopsy is not representative from multiple sites. ${ }^{12}$ Though we have improved the number of samples from the stomach following modified Sydney system than that of the 2004/2005, the result turned out to be similar. This could be due to improved awareness in the community, interobserver variability, increasing number of endoscopy / ERCP as a tertiary care center and overall better patient care.

A declining prevalence of $H$. pylori infection has been reported in the west as well as in Japan. ${ }^{13,14}$ In 1998 Kawasaki et al. reported significant regional variation in prevalence of $H$. pylori infection within Nepal. ${ }^{15}$ Therefore, the lower rate of prevalence in our present study and also the incidence rate of this study compared to our study done 13 years ago could be due to regional variation and also may be due to the effectiveness of $H$. pylori regimen given to our patients.

There are also reports of a higher prevalence of $H$. pylori in industrialized Asian countries (39\% in Japan and $60 \%$ in South Korea both industrialized, affluent countries with safe water supplies) compared to their western counterparts.
This might be due to the potential increase in oral-oral transmission of this infection due to the "family-style" sharing of meals and plates etc. typical in Asian countries. ${ }^{16}$

Our present study showed higher $H$. pylori infection in males than in females with male to female ratio of 1.29:1. However, studies done by others did not show any significant gender difference. ${ }^{15,17}$ The cause of male predominance in our study is not clear. Much larger scale study is required to establish the cause of male predominance. $H$. pylori is the most common infectious etiology associated with chronic gastritis. ${ }^{16}$

It is also the leading cause for endoscopy performed in this institute with $41.4 \%$ of the patient positive with $H$. pylori. There is a clear association between $H$. pylori infection and the development of peptic ulcer disease. The prevalence of peptic ulcer disease caused by $\mathrm{H}$. pylori remains high in Asia at about $93 \%{ }^{18}$ In the United States and in Western Europe the prevalence of peptic ulcer disease have been lowered in the range of $40-75 \%$ due to a declining occurrence of $H$. pylori infection. ${ }^{16}$ Our study also showed lower incidence (28.4\%) of peptic ulcer disease infected with $H$. pylori. Clinical diagnosis with prevalence of $H$. pylori is compared with other studies (Table 2).

Table 2. Clinical manifestations and $\boldsymbol{H}$. Pylori among various studies.

\begin{tabular}{|c|c|c|c|c|}
\hline Clinical manifestation & $\begin{array}{l}\text { Present } \\
\text { study } \\
(\%)\end{array}$ & $\begin{array}{l}\text { KC } \\
\text { et al. }{ }^{7} \\
(\%)\end{array}$ & $\begin{array}{l}\text { Shrestha } \\
\text { et al. }{ }^{19} \\
(\%)\end{array}$ & $\begin{array}{l}\text { Kazi } \\
\text { et al. }{ }^{20} \\
(\%)\end{array}$ \\
\hline Gastritis & 41.4 & 63.9 & 41.1 & 86 \\
\hline Acid disease & 42.7 & - & - & - \\
\hline Gastroduodenits & 37.7 & 71 & - & - \\
\hline Reflux/ esophagitis & 52.7 & 49 & 0.7 & - \\
\hline Gastric Ulcer & 28.4 & 87.3 & 69.5 & 78.5 \\
\hline Duodenal ulcer/erosion & 53.1 & 85 & 84.7 & 84.6 \\
\hline Acute abdomen & 42.3 & - & - & - \\
\hline Erythematous mucosa & 32.4 & - & - & - \\
\hline Hiatal Hernia & 22.6 & - & 0 & - \\
\hline Polyp & 25.7 & - & 20.8 & - \\
\hline UGI bleeding & 40.7 & - & - & - \\
\hline Malignancy & 27.7 & 80 & 11.5 & - \\
\hline Others & 29.0 & - & - & - \\
\hline
\end{tabular}

\section{CONCLUSION}

Most commonly $H$. pylori cause chronic gastritis in our context. Even with large number of biopsy and long period of time, compared to $2004 / 2005$ study, there is no significant change in prevalence of $H$. pylori infection in our part of the world. This could be due to drug resistance and increasing number of relapse cases. This is an alarming sign that many gastrointestinal diseases including gastric cancer will not decrease in future if proper intervention is not taken. 


\section{REFERENCES}

1. Kuo FC, Wu CY, Kuo CH, Wu CF, Lu CY, Chen YH, et al. The utilization of a new immunochromatographic test in detection of Helicobacter pylori antibody from maternal and umbilical cord serum. BioMed research international. 2014 Jan 1;2014.

2. Vilchis J, Duque X, Mera R, Morán S, Torres J, González-Cossío T, et al. Association of Helicobacter pylori infection and height of Mexican children of low socioeconomic level attending boarding schools. The American journal of tropical medicine and hygiene. 2009 Dec 1;81(6):1091-6.

3. Parsonnet J. The incidence of $H$. pylori infection. Aliment Pharmacol Ther. 1995;2:45-51.

4. Makaju RK, Tamang MD, Sharma Y, Sharma N, Koju R, Ashraf M. Prevalence of helicobacter pylori in Dhulikhel Hospital, Kathmandu University Teaching Hospital: A retrospective histopathologic study. Kathmandu Univ Med J. 2005;3(4):355-9

5. Dunn BE, Cohen H, Blaser MJ: Helicobacter pylori. Clin Microbiol Rev. 1997;10:720-41.

6. Colding $\mathrm{H}$, Hartzen $\mathrm{SH}$, Roshanisefat $\mathrm{H}$, Andersen $\mathrm{LP}$, Krogfelt KA. Molecular methods for typing of Helicobacter pylori and their applications. FEMS Immunol Med Microbiol. 1999;24:193-9.

7. KC Shiva Raj, Lakhey A, Koirala K, Amatya GL. Prevalence of Helicobacter pylori among patients with dyspepsia and correlation between endoscopic and histological diagnosis. J Pathol Nepal. 2016;6:942-6.

8. Suk F, Lien G, Yu T, Ho Y. Global trends in Helicobacter pylori research from 1991-2008 analyzed with the Science Citation Index Expanded. Eur J GastroenterolHepatol. 2011;23:295-301.

9. Begue RE, Gonzales JL, Corrrea-Gracian H, Tang SC. Helicobacter pylori infection in children with abdominal ailments in a developing country. Am J Med Sci. 1997;314:279-83.

10. Thapa M, Subedi S, Shakya S, Sharma S, Sharma AP, Choudhury DR. Prevalence of Helicobacter pylori among patients with gastritis and peptic ulcer in Kathmandu Valley, Nepal. Nepal Med College J. 2001;3:15-8.
11. Mur VM, Gimeno EE, Guerrero NL, Cabeza LF, Sainz SR. Prevalence of Helicobacter pylori in gastric pathology in Aragon. Rev Esp Enferm Dig. 1992;82:311-6.

12. Guzman EM, Nevermann KS, Maria L, Echandi A, Davidovich H Comparative study of urease tests for Helicobacter pylori detection in gastric biopsies. Rev Biomed. 1999;10: 145-51.

13. Haruma K, Okamoto $S$, Kawaguchi H, Kamada T, Yoshihara M, Sumii $\mathrm{K}$, et al. Reduced incidence of Helicobacter pylori infection in young Japanese persons between 1970s and 1990s. J Clin Gastroenterol. 1997;25:583-6.

14. Ciociola AA, McSorley DJ, Turner K, Sykes D, Palmer JB. Helicobacter pylori infection rates in duodenal ulcer patients in the United States may be lower than previously estimated. Am J Gastroenterol. 1999;94:1834-4.

15. Kawasaki M, Kawasaki T, Ogaki T, Kobayashi S, Yoshimizu Y, Aoyagi $K$, et al. Seroprevalence of Helicobacter pylori infection in Nepal: low prevalence in an isolated rural village. European journal of gastroenterology \& hepatology. 1998 Jan 1;10(1):47-50.

16. Watari J, Chen N, Amenta PS, Fukui H, Oshima T, Tomita T, et al. Helicobacter pylori associated chronic gastritis, clinical syndromes, precancerous lesions, and pathogenesis of gastric cancer development. World J Gastroenterol. 2014; 20(18): 5461-73.

17. Vithayasai N. Childhood Helicobacter pylori infection, clinical presentations, endoscopic, histologic features and results of treatment. J Med Assoc Thai. 2003;3:600-4.

18. Li Z, Zou D, Ma X, Chen J, Shi X, Gong Y, et al. Epidemiology of peptic ulcer disease: endoscopic results of the systematic investigation of gastrointestinal disease in China. Am J Gastroenterol. 2010;105:25707.

19. Shrestha UK, Ghosh A, MAlurkar V, Kohli SC, Sapkota S. Prevalence of Helicobacter pylori infection, its correlation with gastroduodenal diseases and the incidence of gastric cancer in Nepal. $J$ Adv Intern Med. 2013;02(02):52-60.

20. Kazi JI, Jafarey NA, Alam SM, Zuberi SJ, Kazi AM, Qureshi H, et al. Association of Helicobacter pylori with acid peptic disease in Karachi. J Pak Med Assoc. 1990 Oct;40(10):240-1. 